\title{
High Ki67, Bax, and thymidylate synthase expression well correlates with response to chemoradiation therapy in locally advanced rectal cancers: proposal of a logistic model for prediction
}

\author{
M Kikuchi, ${ }^{*, 2}$, T Mikami', T Sato ${ }^{3}$, W Tokuyama', K Araki', M Watanabe ${ }^{3}, K$ Saigenji' ${ }^{2}$ and I Okayasu' \\ 'Department of Pathology, Kitasato University School of Medicine, Sagamihara, Kanagawa, Japan; ${ }^{2}$ Department of Gastroenterology, Kitasato University \\ School of Medicine, Sagamihara, Kanagawa, Japan; ${ }^{3}$ Department of Surgery, Kitasato University School of Medicine, Sagamihara, Kanagawa, Japan
}

BACKGROUND: Recently, preoperative chemoradiation therapy (CRT) for rectal cancer has been increasingly used as a neoadjuvant treatment. In the present study, the relation between histological response to CRT and immunohistochemical markers in biopsy specimens was investigated.

METHODS: Biopsy specimens from a total of 60 patients were collected before preoperative CRT with S-I and irinotecan, and liniac 45 Gy. Immunohistochemical staining for Ki67, Mcm3, Bax, Bcl-2, ssDNA, Grp78, thymidylate synthase (TS), dihydropyrimidine dehydrogenase (DPD), CD34, vascular endothelial growth factor, nestin, and L-type amino-acid transporter I was performed to allow comparison of the Ki67 labelling index (LI), Bax score, TS score, DPD score, microvessel density by CD34, and Grp78 score with cancer regression.

RESULTS: When the cases were divided into responders (Dworak grades 3 and 4) and non-responders (grades I and 2) groups, good correlations were evident with Ki67 LI, Bax, Grp78, and TS expression. On multiple logistic regression analysis, Ki67 LI, Bax, and TS scores were found to be independent factors. With their use in a logistic model, $P$-values could predict responder cases with a sensitivity of $82.8 \%$ and a specificity of $83.9 \%$.

CONCLUSION: Using this system, treatment strategy for locally advanced rectal cancers can be determined before chemoradiation. British Journal of Cancer (2009) I 0 I, I I6-123. doi:I0.1038/sj.bjc.6605 I05 www.bjcancer.com

Published online 2 June 2009

(c) 2009 Cancer Research UK

Keywords: Ki67; Bax; thymidylate synthase; chemoradiation; rectal cancer

Chemoradiation therapy (CRT) is increasingly used in neoadjuvant approaches for rectal cancer. Although in locally advanced cases there is generally no improvement of overall survival, local control is better than with postoperative CRT (Sauer et al, 2004). Combining irinotecan with 5-fluorouracil (5-FU) and leucovorin (LV) chemotherapy can provide higher rates of tumour regression, progression-free survival, and overall survival for metastatic colorectal cancer (Saltz et al, 2000). Recently, our group has developed a novel protocol for neoadjuvant CRT combining S-1 with irinotecan and radiation, allowing a complete pathological response rate of $31.6 \%$ to be achieved (Sato et al, 2007). It is well established that a pathological complete response (CR) or near CR ( $>95 \%$ pathological response) is significantly linked with improved patient survival (Ruo et al, 2002; Guillem et al, 2005).

$\mathrm{S}-1$ is a novel oral fluoropyrimidine, combining tegafur (FT), 5-chloro-2,4-dihydroxypyridine (gimeracil or CDHP), and potassium oxonate (oteracil potassium or Oxo). FT is a prodrug for

\footnotetext{
* Correspondence: Dr M Kikuchi, Department of Pathology, Kitasato University School of Medicine, I-15-I, Kitasato, Sagamihara, Kanagawa 228-8555, Japan; E-mail: masaomi@kitasato-u.ac.jp

Received 9 February 2009; revised 17 April 2009; accepted 27 April 2009; published online 2 June 2009
}

5-FU that acts as an effector. CDHP reversibly inhibits the degradation of 5-FU by dihydropyrimidine dehydrogenase (DPD), resulting in prolonged high concentrations of 5-FU in the blood (Sato et al, 2007). Irinotecan (CPT-11) inactivates topoisomerase I through the formation of stable topoisomerase I-DNA cleavable complexes (Hsiang et al, 1985; Hsiang and Liu, 1988; Hertzberg et al, 1989). Interaction of the trapped cleavable complex with a replication fork results in replication arrest and fork breakage, finally leading to cell death (D’Arpa and Liu, 1989).

High proliferative activity examined with Ki67 and proliferating cell nuclear antigen (PCNA) staining (Willett et al, 1995), high Bax expression (Chang et al, 2005), and high thymidylate synthase (TS) (Negri et al, 2008) have been demonstrated to predict regression. However, these factors have been treated as univariate factors. No clinically applicable system for prediction of response of CRT has been proposed. We therefore have investigated cell proliferation, apoptosis, apoptosis-associated protein, expression of glucoseregulated protein 78 (Grp78), TS, DPD, and angiogenesis in biopsy samples in an attempt to develop a predictive system. Selection of these parameters was for the following reasons.

Thymidylate synthase provides de novo thymidylate for DNA synthesis, catalysing the methylation of deoxyuridine monophosphate to deoxythymidine monophosphate (Danenberg, 1977). The activity of 5-FU mainly depends on intracellular 
conversion to its active metabolite, 5-fluoro- $2^{\prime}$-deoxyuridine- $5^{\prime}$ monophosphate, which inhibits DNA synthesis by forming a stable complex with TS in presence of folates (Pinedo and Peters, 1988), and then initiates cell-cycle arrest or cell death. In general, high expression of thymidine phosphorylase and low expression of DPD in tumours are considered to result in higher intratumoural concentration of 5-FU (Jakob et al, 2005).

Glucose-regulated protein 78 is a member of the Hsp70 superfamily of heat-shock proteins whose increased expression is part of a coordinated protein response required to alleviate endoplasmic reticulum stress (Misra et al, 2005), maintain endoplasmic reticulum function, and protect cells against cell death. Glucose-regulated protein 78 may confer resistance against adriamycin- and etoposide-mediated apoptosis in cancer cells through inhibition of Bax and caspase-7 activation (Reddy et al, 2003; Davidson et al, 2005; Ermakova et al, 2006; Lee et al, 2006; Ranganathan et al, 2006).

Recently, the concept of cancer stem cells has attracted increasing attention with regard to human cancers (Wang and Dick, 2005). Minichromosome maintenance $(\mathrm{Mcm})$ proteins 2-7 are present through all phases of the proliferative cell cycle, but are absent in 'out-of-cycle' states, suggesting functions as replication licensing factors (Stoeber et al, 2001), and Dudderidge et al (2005) have proposed that the Mcm2-Ki67 labelling index (LI) reflects the presence of non-proliferating dormant 'cancer stem' cells, associated with reduced disease-free survival in renal cell carcinoma cases.

It was reported that high intratumoural microvessel density (MVD) and vascular endothelial growth factor (VEGF) were correlated with poor prognosis of colorectal cancer (Des Guetz et al, 2006). It has been also reported that VEGF-positive rectal cancer was resistant to radiotherapy (Zlobec et al, 2008). Nestin, a class VI intermediate filament protein, has recently received attention as a marker for detecting newly formed endothelial cells (Teranishi et al, 2007).

As for apoptosis, cancer cell apoptosis in biopsy before CRT was correlated with tumour regression whereas apoptosis inhibitory protein Bcl-2 expression indicated no correlation with regression (Rödel et al, 2002). In addition, L-type amino-acid transporter 1 (LAT1) is highly expressed in malignant tumours to support growth and proliferation, and the inhibition of LAT1 activity led to cancer cell apoptosis (Kim et al, 2008).

Using these parameters, multiple logistic regression analysis was adopted to generate a model for predicting response to preoperative CRT.

\section{MATERIALS AND METHODS}

A total of 60 cases of rectal cancer treated with preoperative CRT were collected. The patients' clinical criteria were previously reported (Sato et al, 2007). Briefly, all had previously untreated locally advanced distal rectal cancer T3 or T4, N0-2, and M0 (UICC classification) (Sobin and Wittekind, 2002), with an Eastern Cooperative Oncology Group performance status of 0-2 (Oken et al, 1982). Ages were 20-80 years at enrolment.

Biopsy materials of the 60 cases were endoscopically obtained from the rectal cancers before the initiation of therapy, at least two pieces of carcinoma being sampled for each case. The histological typing was in accordance with the WHO classification (Hamilton and Aaltonen, 2000). Tumour size was measured using doublecontrast barium enema in 56 cases, but no X-ray photographs were available for 4 cases. Clinical tumour node metastasis (TNM) stage was judged with computed tomographic scans and/or magnetic resonance images. Because images were not available for two cases, clinical TNM stage could not be determined for these. A summary of clinical data of the cases is shown in Table 1. All patients received preoperative chemoradiation as follows: radiotherapy was
Table I Characteristics of the patients

\begin{tabular}{|c|c|}
\hline \multicolumn{2}{|l|}{ Characteristic } \\
\hline Age (year) (mean \pm s.d.) $(n=60)$ & $63.9 \pm 10.6($ range $32-81)$ \\
\hline Sex (male/female) $(n=60)$ & $44(73.3 \%) / 16(26.7 \%)$ \\
\hline Tumour size $(\mathrm{mm})($ mean \pm s.d. $)(n=56)$ & $47.4 \pm 17.2($ range $20-95)$ \\
\hline \multicolumn{2}{|l|}{ Clinical T stage $(n=58)$} \\
\hline сT3 & 56 \\
\hline cT4 & 2 \\
\hline \multicolumn{2}{|l|}{ Clinical $N$ stage $(n=58)$} \\
\hline cNO & 32 \\
\hline $\mathrm{cNI} / \mathrm{cN} 2$ & 26 \\
\hline \multicolumn{2}{|l|}{ Histological type (biopsy) $(n=60)$} \\
\hline Well & 36 \\
\hline Moderate & 23 \\
\hline Poor & I \\
\hline CEA $(\mathrm{mg} / \mathrm{l} 00 \mathrm{ml})($ mean $\pm \mathrm{s} . \mathrm{d}).(n=60)$ & $8.9 \pm 12.7$ \\
\hline CAl9-9 $(\mathrm{ng} / \mathrm{ml})($ mean \pm s.d. $)(n=60)$ & $19.7 \pm 27.2$ \\
\hline
\end{tabular}

s.d., standard deviation. Normal ranges of CEA and CA19-9 were $<5 \mathrm{mg} / 100 \mathrm{ml}$ and $<37 \mathrm{ng} / \mathrm{ml}$, respectively. Tumour size (based on double-contrast barium enema), clinical TN stage, and tumour markers were evaluated before chemoradiation therapy.

administered in liniac fractions of $1.8 \mathrm{~Gy}$ per day, 5 days per week. The total dose of radiation was $45 \mathrm{~Gy} . \mathrm{S}-1\left(80 \mathrm{mg} \mathrm{m}^{-2}\right.$ per day) and was given orally after breakfast and dinner on days $1-5,8-12$, $22-26$, and $29-33$. Irinotecan $\left(80 \mathrm{mg} \mathrm{m}^{-2}\right)$ was administered as a continuous i.v. infusion for 90 min on days $0,8,22$, and 29. Radical surgery was performed at least 4-6 weeks after the completion of 5 weeks of chemoradiation. The dose of S-1 was in accordance with the manufacturer's guideline (Taiho Pharmaceuticals Co. Ltd, Tokyo, Japan). The recommended dose of irinotecan was examined in our previous study (Sato et al, 2007). This protocol was started in 2004 with approval of the ethics committee of Kitasato University Hospital. All patients gave written informed consent.

\section{Pathological evaluation}

Therapeutic responses to preoperative CRT were evaluated with the surgically resected specimens. The excised tissues were fixed in buffered formalin and embedded in paraffin. In each case, the entire lesion was serially sliced at $4 \mathrm{~mm}$ for routine processing and embedding in paraffin. Then, $4-\mu \mathrm{m}$-thick sections were cut, stained with haematoxylin and eosin, and examined by light microscopy. Amounts of residual tumour mass, fibrotic changes, radiation vasculopathy, and peritumoural inflammatory reaction were checked, and therapeutic effects were assessed using Dworak grades (Dworak et al, 1997) as follows:

grade 0: no regression;

grade 1: dominant tumour mass with obvious fibrosis and/or vasculopathy;

grade 2: dominant fibrotic changes with few tumour cells or groups (easy to find);

grade 3: very few tumour cells in fibrotic tissue with or without mucous substance;

grade 4: no tumour cells, only fibrotic mass (total regression).

Immunohistochemistry of Ki67, Mcm3, Bax, Bcl-2, ssDNA, Grp78, TS, DPD, CD34, VEGF, nestin, and LAT1

Formalin fixed, paraffin-embedded histological sections $(4 \mu \mathrm{m}$ in thickness) in tumour biopsies before CRT were immunostained for 12 antigens (Ki67, Mcm3, Bax, Bcl-2, ssDNA, Grp78, TS, DPD, CD34, VEGF, nestin, and LAT1). The antibodies used and methods 
Table 2 Antibodies used for the immunohistochemical study

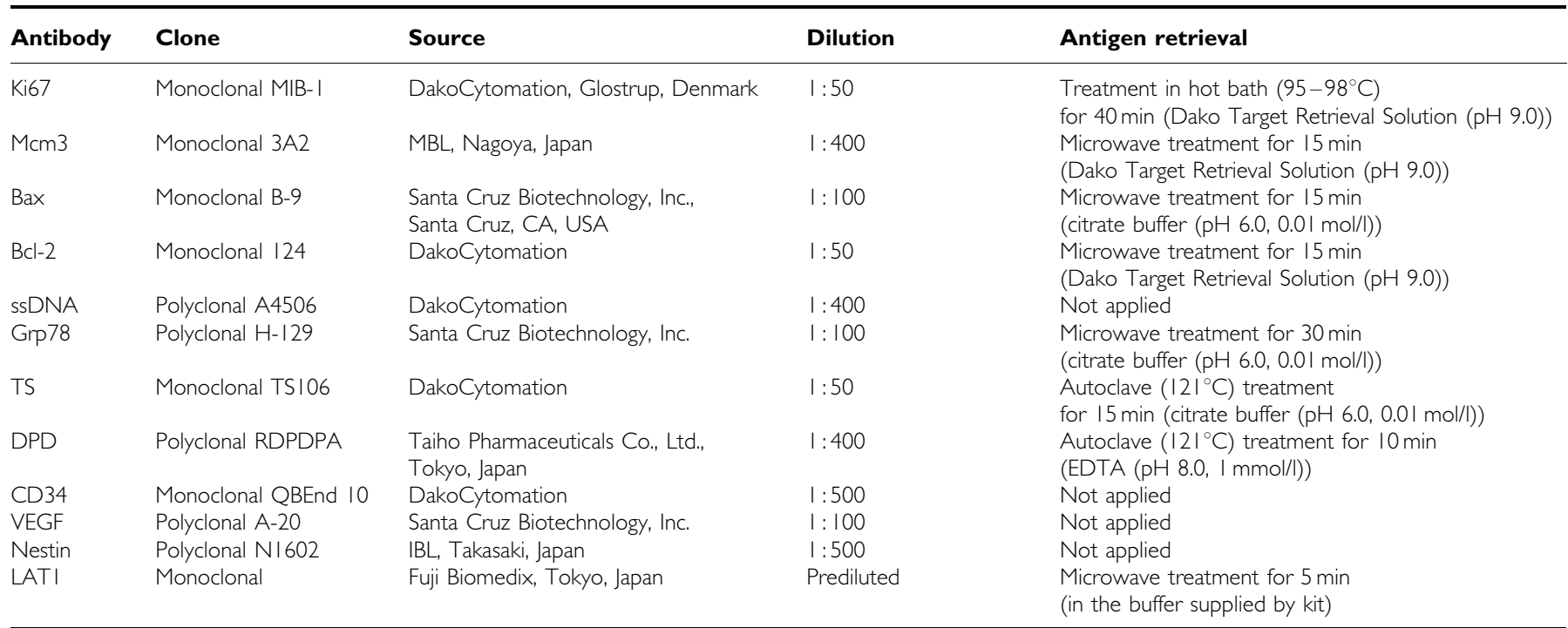

Mcm, minichromosome maintenance; Grp78, glucose-regulated protein 78; TS, thymidylate synthase; DPD, dihydropyrimidine dehydrogenase; VEGF, vascular endothelial growth factor; LATI, L-type amino-acid transporter I.

for antigen retrieval are listed in Table 2. Endogenous peroxidase was blocked with $3.0 \%$ hydrogen peroxide for $10 \mathrm{~min}$, and incubation with Protein block serum-free solution (DakoCytomation, Glostrup, Denmark) for $10 \mathrm{~min}$. Sections were incubated with the anti-Ki67, Bax, Grp78, TS, DPD, and CD34 primary antibodies for $60 \mathrm{~min}$ at room temperature, and with the anti$\mathrm{Mcm} 3$, Bcl-2, ssDNA, VEGF, and nestin antibodies overnight at $4{ }^{\circ} \mathrm{C}$. After incubation with either labelled polymer, anti-mouse, or anti-rabbit (EnVision + System HPR; DakoCytomation) for $60 \mathrm{~min}$ at room temperature, 3,3'-diaminobenzidine was used as the chromogen. Nuclei were counterstained with methyl green solution to facilitate histopathological assessment. The immunohistochemical protocol with the LAT1 staining kit (Fuji Biomedix, Tokyo, Japan) was according to the manufacturer's manual.

\section{Evaluation of immunohistochemical staining}

Ki67 and Mcm3 LI were determined as percentage values counting at least 1000 tumour cells in high-power fields $(\times 400)$. With ssDNA staining, immunohistochemically positive cells were so few in number that at least 5000 nuclei were counted. ssDNA indices also were determined as percentage values.

Immunoreactivity for Bax, Bcl-2, Grp78, TS, DPD, and VEGF was evaluated using a score based on the classification of Sinicrope et al (1995). The staining intensity was scored as follows: none, 0; weak, 1 ; moderate, 2 ; intense, 3 . If heterogeneity of staining intensity existed in a section, the staining intensity was scored based on that which was predominantly observed. The percentages of positive cells were assigned to one of five categories of protein expression: 0 , $\leqslant 5 \% ; 1,5-25 \% ; 2,25-50 \% ; 3,50-75 \% ; 4, \geqslant 75 \%$. The two scores were then multiplied to produce a weighted score for each tumour specimen. Two pathologists (MK and TM) independently scored the lesions and determined the final scores by discussion when they differed.

CD34-expressing capillaries were counted to give the MVD. Nestin-examined capillaries were considered as capillaries consisting of newly formed endothelial cells (Teranishi et al, 2007). Areas of highest neovascularisation were found by scanning tumour sections at low power $(\times 100)$. The highest vascular counts of two different fields were averaged and used to calculate numbers of microvessels per $\mathrm{mm}^{2}$, defined as MVD with both stainings.
For LAT1, a biomarker for high-grade malignancy, staining intensity was scored according to a previous report (Sakata et al, 2009): none, 0 ; weak, 1; moderate, 2 ; intense, 3 . The percentages of positive cells were assigned to one of four categories: $0,<0 \% ; 1$, $1-10 \% ; 2,10-30 \% ; 3,>30 \%$. The values for the two variables were then multiplied, resulting in a scoring from 0 to 9. Two pathologists (MK and TM) independently scored the lesions.

\section{Statistical analysis}

Data were analysed using Dr. SPSS II (SPSS, Chicago, IL, USA) and Statview 5.0 (SAS Institute Inc., Cary, NC, USA) software. Immunohistochemical labelling and scores were compared using the Kruskal-Wallis test and the Mann-Whitney $U$-test. Logistic regression analysis was performed with a stepwise method. $P<0.05$ was considered as statistically significant.

\section{RESULTS}

\section{Pathological response to CRT}

Pathological evaluation of responses to preoperative CRT in resected rectum revealed radiation effects in all cases, with fibrosis and vascular changes. All 60 cases were classified into Dworak regression grades $1-4$. Of these, 15 (25.0\%) showed complete pathological responses (regression grade 4$)$ and 14 (23.3\%) showed microscopic residual tumours (regression grade 3 ), whereas 21 $(35.0 \%)$ and $10(16.7 \%)$ showed moderate (regression grade 2 ) or minimal (regression grade 1) responses to preoperative CRT, respectively.

Ki67, Mcm3, and ssDNA expression was confined to tumour cell nuclei, and Bax, Bcl-2, Grp78, and VEGF immunoreactivity to the tumour cell cytoplasm. TS and DPD were expressed in both nuclei and cytoplasm. LAT1 was confined to cell membranes, and CD34 and nestin were expressed in endothelium of intratumoural microvessels (Figure 1).

Figure 2 demonstrates the relationship between each immunohistochemical marker of the tumour biopsies before CRT and the pathological tumour response. A high Ki67 LI, Bax score, TS score, DPD score, MVD by CD34, and a low Grp78 score correlated with regression on univariate analysis. Recent studies have revealed that 

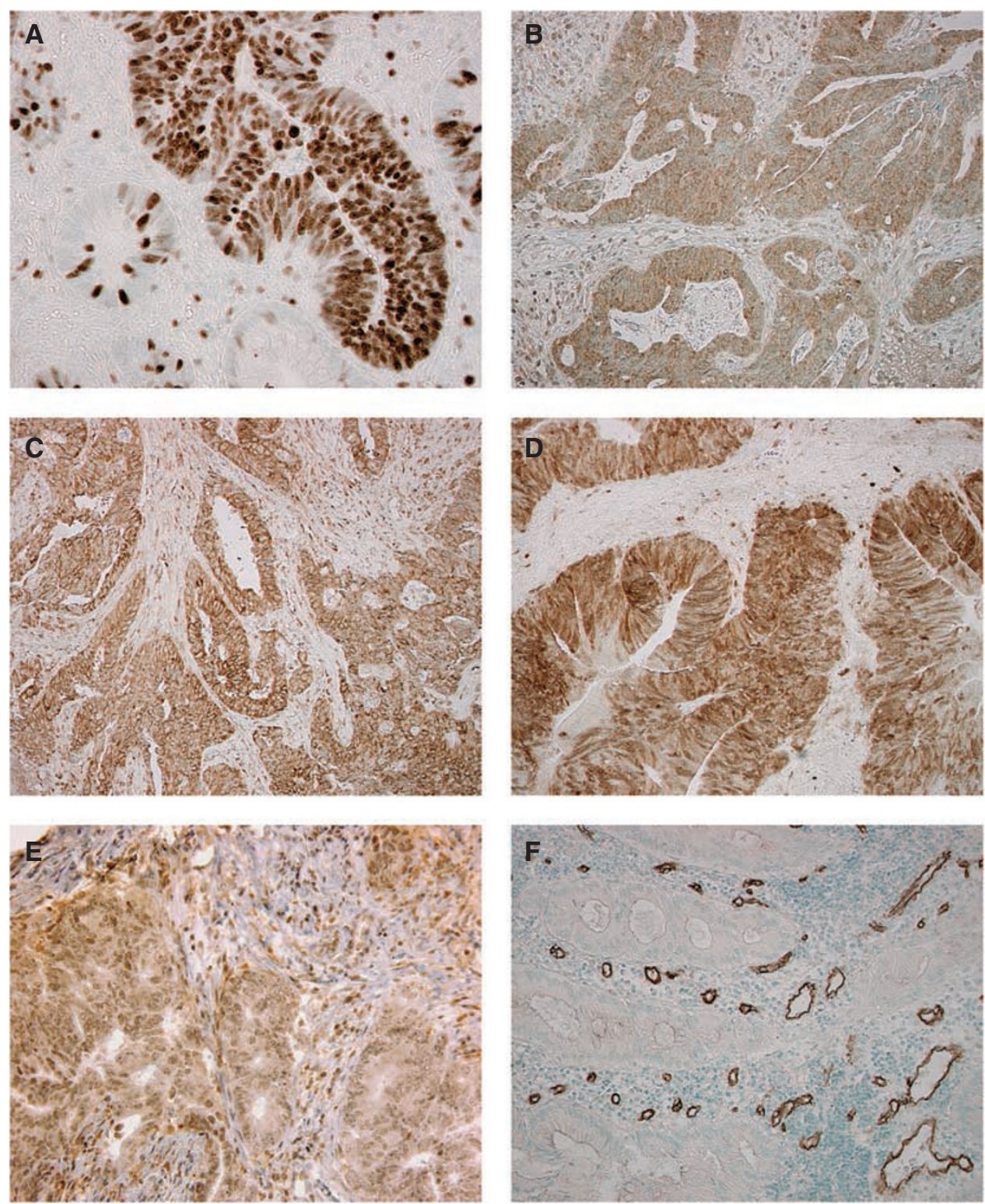

Figure I Immunohistochemical staining of pre-treatment rectal biopsy specimens from locally advanced rectal cancers. (A) Ki67 immunoreactivity, (B) Bax immunoreactivity, (C) Grp78 immunoreactivity, (D) TS immunoreactivity, (E) DPD immunoreactivity, and (F) CD34 immunoreactivity. Note Ki67 immunoreactivity confined to the tumour cell nuclei, Bax, and Grp78 to the tumour cell cytoplasm, TS and DPD to the tumour cell nucleus and cytoplasm, and CD34 to the endothelium of intratumoural microvessels.

pathological CR and greater than $95 \%$ pathological response groups achieve a significantly improved overall survival and recurrence-free survival when compared with less than $95 \%$ pathological response groups (Ruo et al, 2002; Guillem et al, 2005). Therefore, we divided the cases into two groups: Dworak grades 1 and 2, and grades 3 and 4 (Gavioli et al, 2005). The latter were considered as responders to CRT. A high Ki67, Bax score, and TS score and a low Grp78 score were well correlated with response. On the other hand, there were no associations with the other immunohistochemical factors, as well as clinicopathological factors (Table 3 ).

\section{Multiple logistic regression analysis}

Multiple logistic regression analysis was performed with a stepwise method (Tanaka et al, 1999). Independent variables were the data for Ki67 LI, Bax score, TS score, and Grp78 score, and dependent variables were no-response (0; Dworak regression grades 1 and 2) or response (1; Dworak regression grades 3 and 4). Other immunohistochemical markers and clinicopathological factors were not used. By the logistic regression analysis, we detected the Ki67 LI, Bax score, and TS score as independent factors (Table 4). The Bax score (odds ratio 18.1) had the strongest influence. The logistic regression formula was as follows:

$$
\begin{aligned}
& \log _{\mathrm{e}}(p / 1-p)=-24+0.15 \times\left[\mathrm{Ki}_{67} \mathrm{LI}\right]+2.90 \\
& \quad \times[\text { Bax score }]+0.60 \times[\text { TS score }] .
\end{aligned}
$$

\section{Receiver-operating characteristic curve}

A receiver-operating characteristic curve was generated by plotting the true-positive rate (sensitivity) on the $y$ axis and the 

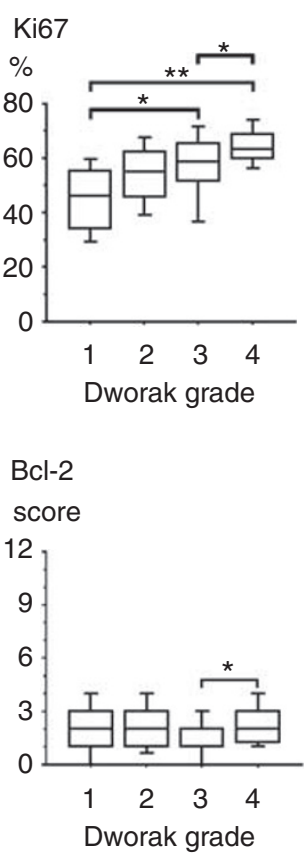

TS
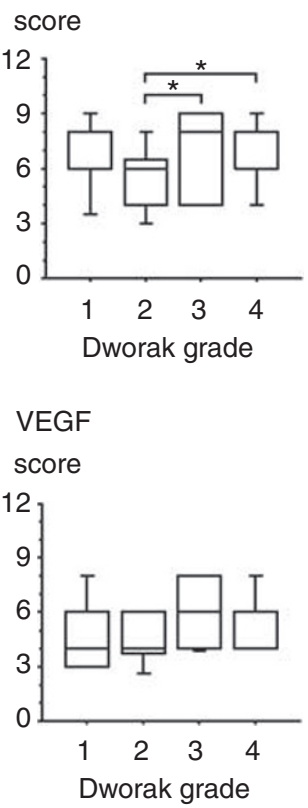
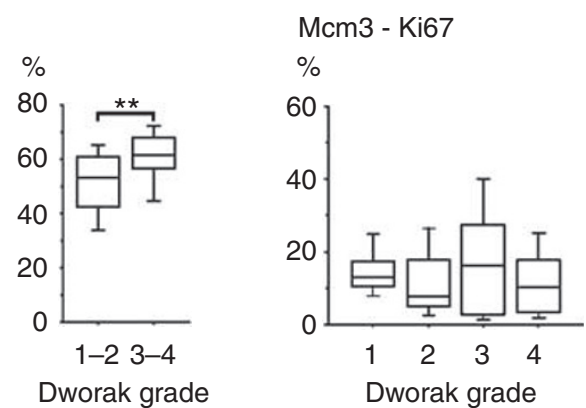

ssDNA

score

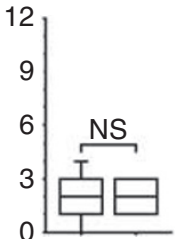

1-2 3-4

Dworak grade
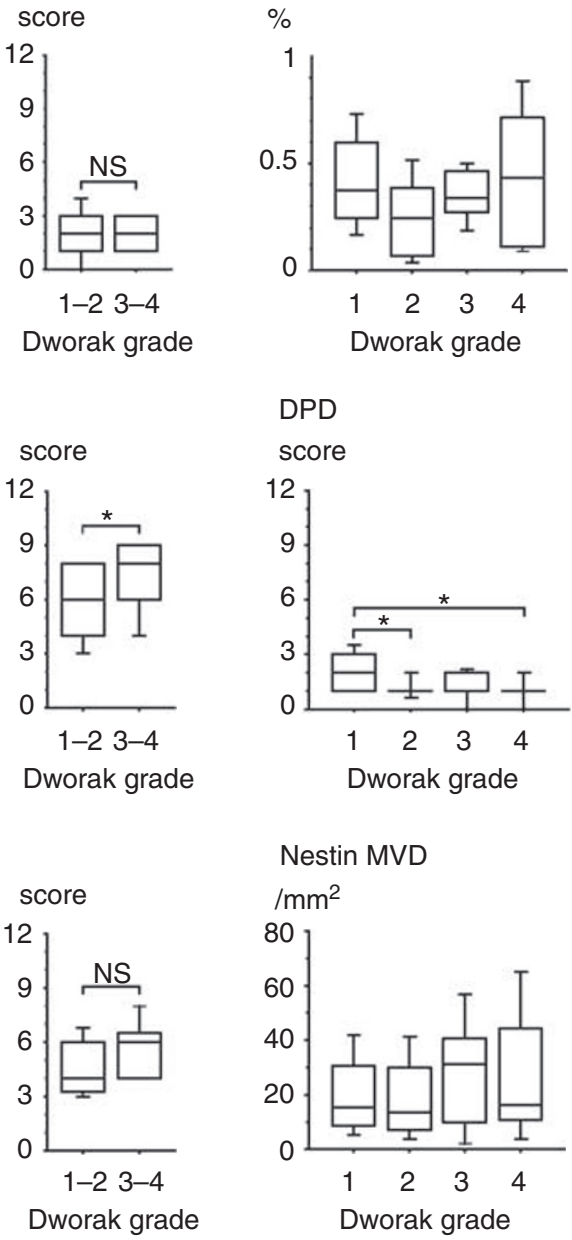
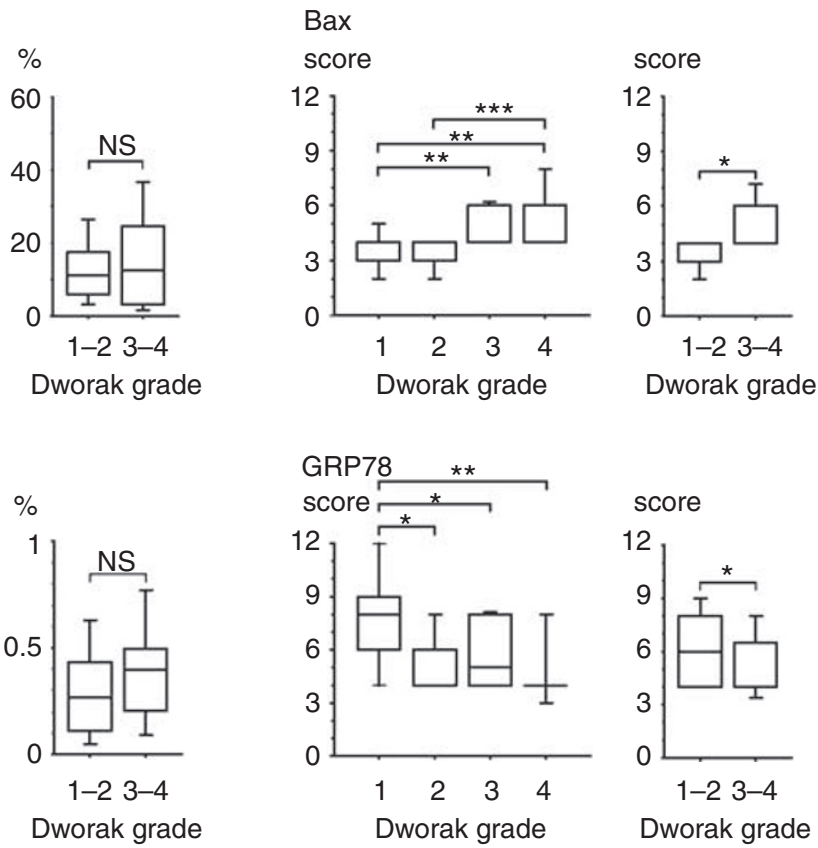

score
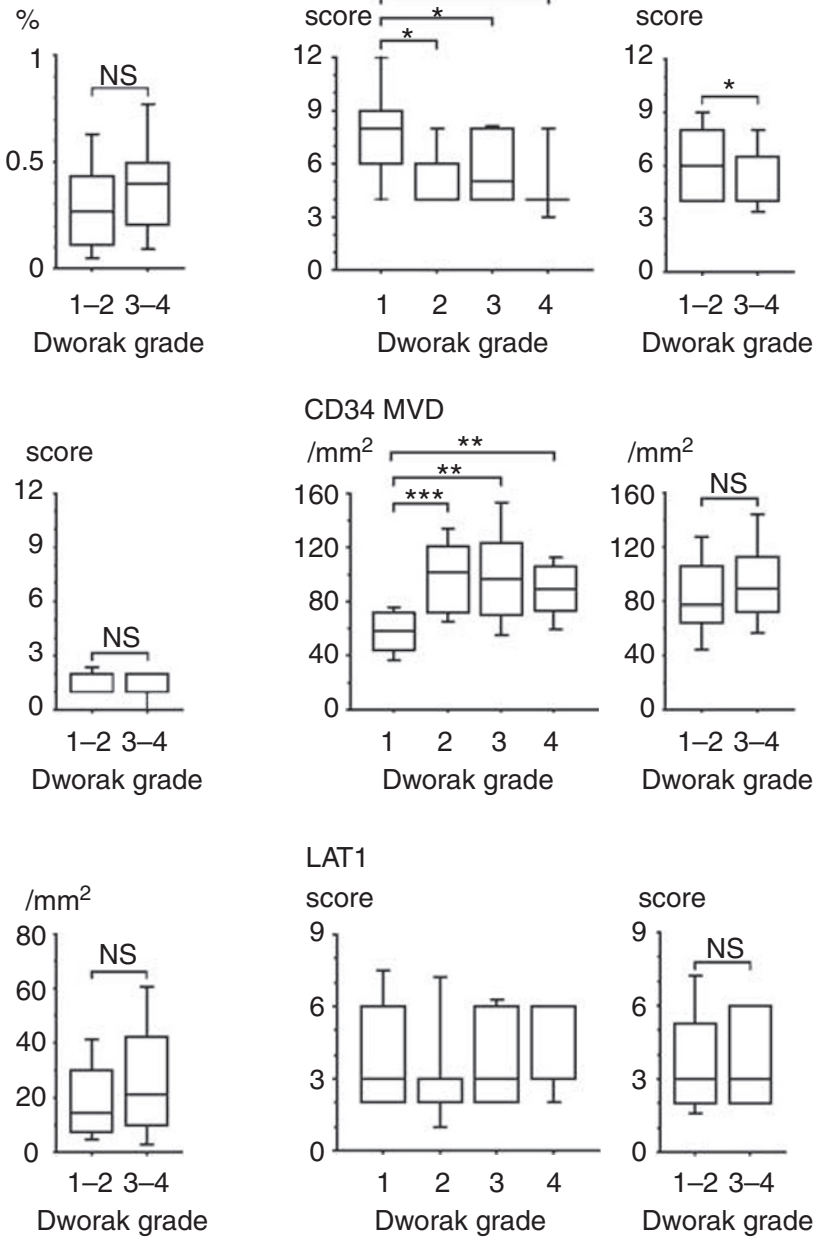

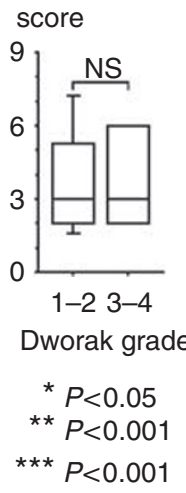

Figure 2 Ki67, Bax, Grp78, TS, DPD, and CD34 (MVD) were significantly related to chemoradiosensitivity $(P<0.05)$. High Ki67 LI, Bax score, TS score, and low Grp78 were significantly correlated with tumour regression when responders were defined as having Dworak regression grades 3 and 4.

false-positive rate (1-specificity) on the $x$ axis (Figure 3 ) (Tanaka et al, 1999).

Although the $P$-value at the point closest to the left upper corner on the curve is generally considered to represent the best balance of both sensitivity and specificity in distinguishing between response and no-response, we determined four points of $P$ as the cut-off values $(0.90,0.50,0.40$, and 0.20$)$ to construct practical criteria for the five categories 'responder', 'probable responder', 'unknown', 'probable non-responder', and 'non-responder' (Table 5). The points of $P=0.90$ and 0.20 meant the points of specificity $100 \%$ and sensitivity $100 \%$, respectively. The point of $P=0.50$ meant the point at which the specificity was maximum and the sensitivity was more than $80 \%$. The point of $P=0.40$ meant the point at which the specificity for prediction of nonresponder was maximum and the sensitivity more than $80 \%$.

\section{Sensitivity and specificity}

A $P$-value for each case was calculated with three immunohistochemical markers examined in 60 sets of biopsy specimens. Using 
the calculated $P$-value, we classified the 60 patients into one of the above five categories with criteria distinguishing between responder and non-responder. Sensitivities and specificities of the criteria are shown in Table 5.

\section{DISCUSSION}

In this study, we sought clinicopathological factors and immunohistochemical markers that might contribute to prediction of chemoradiation effects on locally advanced rectal cancer. Our conclusion is that it is possible to predict a responder to preoperative CRT, with $82.8 \%$ sensitivity and $83.9 \%$ specificity, using the value calculated with the three elements of the Ki67 LI, the Bax score, and the TS score in biopsy specimens before CRT. In

Table 3 Clinicopathological characteristics of the patients separated by Dworak grades 1, 2 vs 3, 4

\begin{tabular}{|c|c|c|c|}
\hline & $\begin{array}{c}\text { Dworak } \\
\text { grade } 3,4 \\
\text { (responder) } \\
(n=29)\end{array}$ & $\begin{array}{c}\text { Dworak } \\
\text { grade I, } 2 \\
\text { (non-responder) } \\
(n=3 I)\end{array}$ & \\
\hline $\begin{array}{l}\text { Age (year) (mean } \pm \text { s.d.) } \\
\text { Sex }\end{array}$ & $63.5 \pm 11.4$ & $63.5 \pm 9.8$ & $P=0.11$ \\
\hline \multicolumn{4}{|l|}{ Sex } \\
\hline Female & 8 & 7 & $P=0.65$ \\
\hline $\begin{array}{l}\text { Tumor size }(\mathrm{mm}) \\
(\text { mean } \pm \text { s.d.) }\end{array}$ & $46.7 \pm 14.4$ & $48.0 \pm 19.7$ & $P=0.98$ \\
\hline \multicolumn{4}{|l|}{ Histological type (biopsy) } \\
\hline $\begin{array}{l}\text { Well } \\
\mathrm{mod} / \mathrm{por}\end{array}$ & $\begin{array}{l}17 \\
12\end{array}$ & $\begin{array}{l}20 \\
11\end{array}$ & $P=0.64$ \\
\hline $\begin{array}{l}\text { CEA (mg/l } 00 \mathrm{ml}) \\
(\text { mean } \pm \text { s.d.) }\end{array}$ & $8.5 \pm 12.7$ & $9.4 \pm 8.5$ & $P=0.23$ \\
\hline $\begin{array}{l}\text { CAI9-9 (ng/ml) } \\
\text { (mean } \pm \text { s.d.) }\end{array}$ & $17 \pm 25$ & $22 \pm 29$ & $P=0.054$ \\
\hline
\end{tabular}

Well, well-differentiated adenocarcinoma; mod/por, moderately to poorly differentiated adenocarcinoma; s.d., standard deviation.

Table 4 Results of multiple logistic regression analysis

\begin{tabular}{lcccc}
\hline & Regression coefficient & P-value & Odds ratio & $\mathbf{9 5 \%} \mathbf{C l}$ \\
\hline Variable & & & & \\
Ki67 LI & 0.15 & 0.002 & 1.17 & $1.06-1.29$ \\
Bax score & 2.90 & 0.001 & 18.1 & $3.11-105.7$ \\
TS score & 0.60 & 0.019 & 1.83 & $1.11-3.03$ \\
Constant & -24.47 & $<0.001$ & & \\
\hline
\end{tabular}

$\mathrm{LI}$, labelling index; $\mathrm{Cl}$, confidence interval. fact, high expression of Ki67, Bax, and TS was positively correlated with therapeutic effects.

The first factor, high proliferative activity with Ki67 as the marker, was earlier found to correlate with PCNA immunostaining, and mitotic counts after radiation of rectal cancer (Willett et al, 1995). Later, beneficial effects of radiotherapy for patients with various carcinoma with high Ki67 LIs were reported (Nakano et al, 1997; Raybaud-Diogene et al, 1997). However, in other reports, no relation was noted between Ki67 values in biopsy specimens before radiation and response rate in rectal cancers (Suzuki et al, 2004; Debucquoy et al, 2008). Suzuki et al (2004) performed preoperative radiotherapy only. Debucquoy et al (2008) combined preoperative radiotherapy and/or 5-FU/LV. Because we adopted CRT for all patients, the response may be more influenced by chemotherapy than radiation.

The second factor, Bax expression, was also reported by Chang et al (2005) to correlate well with chemoradiation therapeutic effects, and the authors considered that apoptosis may be important in rectal carcinoma response to CRT. Similarly, Bax overexpression has been found to correlate with anticancer drug sensitivity in a variety of human cancers, through enhanced induction of apoptosis (Krajewski et al, 1995; Guo et al, 2000; Teranishi et al, 2007). However, Gosens et al (2008) did not find any link between Bax expression and rectal cancer regression for neoadjuvant chemoradiation. They evaluated the regression grading system described by Rödel et al (2005): (1) no regression or $<25 \%$ of tumour mass, (2) 25 to $>50 \%$ tumour regression, and

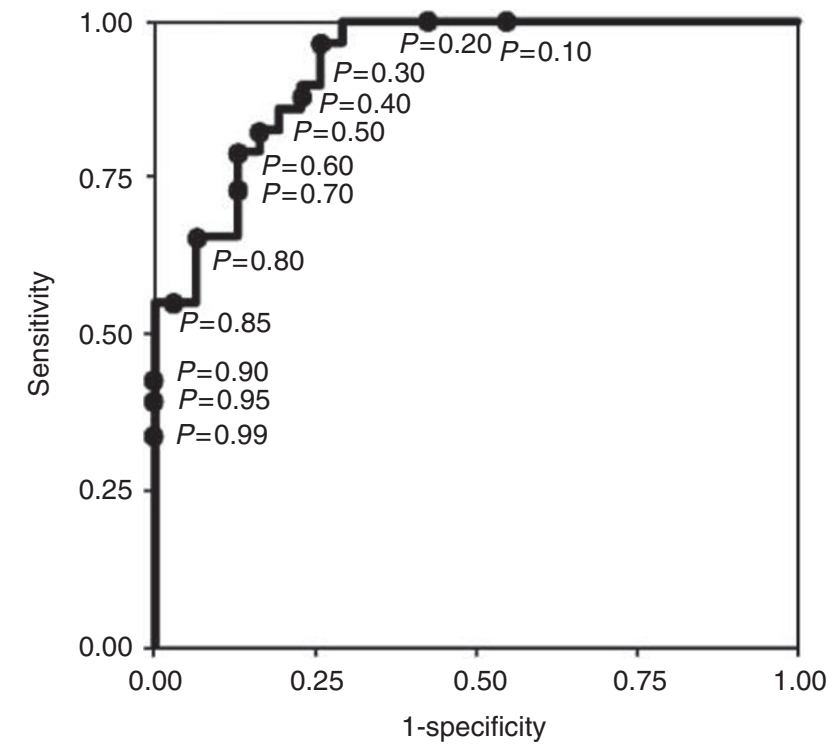

Figure 3 Receiver-operating characteristic curve with the logistic regression model. The area under the curve is 0.928 ( $95 \%$ confidence interval; 0.867-0.988).

Table 5 Criteria for Dworak grades I, 2 vs 3, 4, and their validities tested among the 60 patients

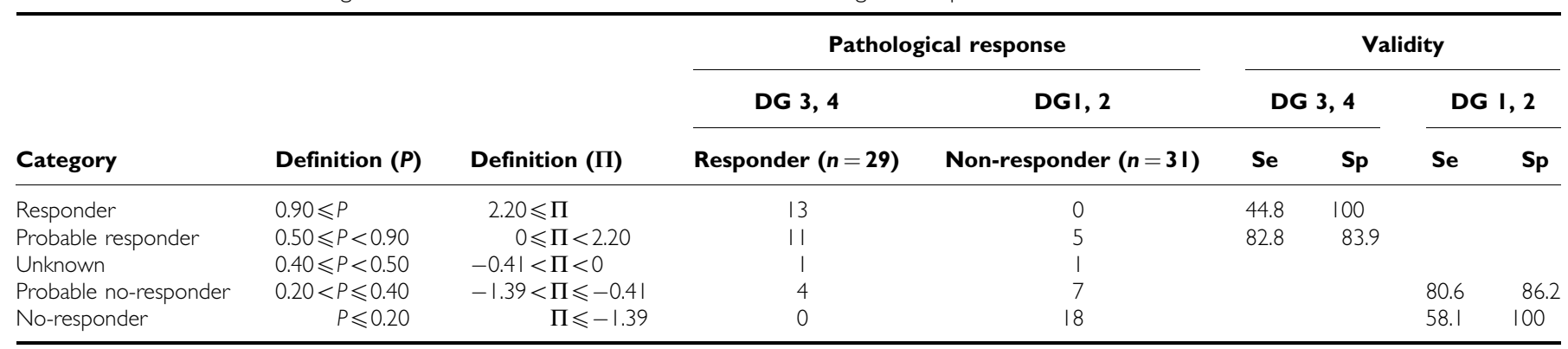

P, probability; DG, Dworak grade; Se, sensitivity; Sp, specificity; $\Pi=\log _{e}(P / I-P)$. 
(3) complete regression. In addition, Bax immunohistochemical values were only intensity of cytoplasmic staining $0-3$. Differences in grading systems and immunohistochemical expression scoring could clearly influence the results.

Rau et al (2003) immunohistochemically investigated the expression of $\mathrm{p} 53, \mathrm{Bax}, \mathrm{p} 21, \mathrm{Ki} 67, \mathrm{hMSH} 2$ in pre- and posttherapeutic rectal carcinoma with preoperative radiotherapy. Only low p21 expression in tumour samples was significant in noresponse to neoadjuvant chemoradiation. They reported no relation with Bax expression but classified responders as CR or partial response, histopathologically defined with resected posttherapeutic rectum, again differing from our definition as Dworak grades 3 or 4 .

The third factor, TS, is important in pyrimidine nucleotide synthesis and represents an important chemotherapeutic target for 5-FU chemotherapy. Immunohistochemically, high TS expression in pre-treatment locally advanced rectal cancer biopsies was earlier shown to be predictive of a higher pathological response in the fluorouracil/oxaliplatin-base chemotherapy (Negri et al, 2008). A trend toward a direct correlation between the level of TS expression and response of 5-FU/LV treatment in patients with metastatic colon cancer has been noted (Johnston et al, 2003). Similar results have also been reported by Edler et al (2002) and Kornmann et al (2003).

However, low TS expression was a predictor of response to 5-FU chemotherapy for colorectal cancer metastases (Aschele et al, 1999) and advanced colorectal cancer (Cascinu et al, 1999). Aschele et al (1999) used a regimen of schedule-specific biochemical modulation of 5-FU plus methotrexate, and Cascinu et al (1999) applied 5-FU/LV. In both studies, cases with metastases and/or recurrence were included, and TS expression was evaluated as intensity 0 (undetectable staining) to 4 (very high intensity of staining), and then intensity levels $0-2$ were considered as low, and 3 and 4 as high expression. We examined both cytoplasmic TS expression intensity and percentage of positive cells, as well as the Bax value. In another study, by Liersch et al (2006), TS expression was examined in surgically resected rectal cancer. In the reports, high TS expression correlated with cancer relapse. The clinical meaning of evaluation of TS expression needs further clarification.

The multiple logistic regression analysis revealed Ki67 LI, Bax score, and TS score to be independent factors, with a sensitivity and specificity for prediction of responder cases of 82.8 and $83.9 \%$, respectively. Although the logarithm model is difficult to calculate for daily use, it can be easily converted to a linear model. It is sufficient for users to know the values of $\log _{\mathrm{e}}(P / 1-P)$ at the point of criteria. Practically, users can directly substitute the Ki67 LI, Bax score, and TS score into the formula:

$$
\begin{aligned}
& \prod=\log _{\mathrm{e}}(\mathrm{p} / 1-\mathrm{p})=-24+0.15 \times[\mathrm{Ki} 67 \mathrm{LI}]+2.90 \\
& \quad \times[\text { Bax score }]+0.60 \times[\text { TS score }] .
\end{aligned}
$$

If this value $\Pi\left(\log _{e}(P / 1-P)\right)$ is larger than 0.00 , it indicates a responder case. If it is smaller than -0.41 , it indicates a nonresponder case (Table 5).

At present, CRT with subsequent surgical resection is performed without selection of cases. However, with our approach, likely responder cases can be chosen before therapy. In the future, our multivariate model should be revised using new factors to improve the sensitivity and specificity. The treatment strategy for locally advanced rectal cancer should be further developed toward socalled tailor-made therapy including such evaluation before preoperative therapy and/or surgical resection.

\section{ACKNOWLEDGEMENTS}

We thank Ms Y Numata, Ms K Hana, and Ms T Tsuruta for their expert technical assistance and Dr Malcolm Moore for revision of the scientific English language. We acknowledge Taiho Pharmaceuticals Co., Ltd., for providing us anti-DPD antibody. This study was partly supported by Parents Association Grant of Kitasato University School of Medicine.

\section{REFERENCES}

Aschele C, Debernardis D, Casazza S, Antonelli G, Tunesi G, Baldo C Lionetto R, Maley F, Sobrero A (1999) Immunohistochemical quantitation of thymidylate synthase expression in colorectal cancer metastases predicts for clinical outcome to fluorouracil-based chemotherapy. J Clin Oncol 17: $1760-1770$

Cascinu S, Aschele C, Barni S, Debernardis D, Baldo C, Tunesi G, Catalano V, Staccioli MP, Brenna A, Muretto P, Catalano G (1999) Thymidylate synthase protein expression in advanced colon cancer: correlation with the site of metastasis and the clinical response to leucovorin-modulated bolus 5-fluorouracil. Clin Cancer Res 5: 1996-1999

Chang HJ, Jung KH, Kim DY, Jeong SY, Choi HS, Kim YH, Sohn DK, Yoo BC, Lim SB, Kim DH, Ahn JB, Kim IJ, Kim JM, Yoon WH, Park JG (2005) Bax, a predictive marker for therapeutic response to preoperative chemoradiotherapy in patients with rectal carcinoma. Hum Pathol 36: $364-371$

D'Arpa P, Liu LF (1989) Topoisomerase-targeting antitumor drugs. Biochim Biophys Acta 989: 163-177

Danenberg PV (1977) Thymidylate synthetase - a target enzyme in cancer chemotherapy. Biochim Biophys Acta 473: 73-92

Davidson DJ, Haskell C, Majest S, Kherzai A, Egan DA, Walter KA, Schneider A, Gubbins EF, Solomon L, Chen Z, Lesniewski R, Henkin J (2005) Kringle 5 of human plasminogen induces apoptosis of endothelial and tumor cells through surface-expressed glucose-regulated protein 78 . Cancer Res 65: $4663-4672$

Debucquoy A, Libbrecht L, Roobrouck V, Goethals L, McBride W, Haustermans K (2008) Morphological features and molecular markers in rectal cancer from 95 patients included in the European Organisation for Research and Treatment of Cancer 22921 trial: prognostic value and effects of preoperative radio (chemo) therapy. Eur J Cancer 44: $791-797$

Des Guetz G, Uzzan B, Nicolas P, Cucherat M, Morere JF, Benamouzig R, Breau JL, Perret GY (2006) Microvessel density and VEGF expression are prognostic factors in colorectal cancer. Meta-analysis of the literature. Br J Cancer 94: 1823 - 1832

Dudderidge TJ, Stoeber K, Loddo M, Atkinson G, Fanshawe T, Griffiths DF, Williams GH (2005) Mcm2, Geminin, and KI67 define proliferative state and are prognostic markers in renal cell carcinoma. Clin Cancer Res 11: $2510-2517$

Dworak O, Keilholz L, Hoffmann A (1997) Pathological features of rectal cancer after preoperative radiochemotherapy. Int J Colorectal Dis 12: $19-23$

Edler D, Glimelius B, Hallstrom M, Jakobsen A, Johnston PG, Magnusson I, Ragnhammar P, Blomgren H (2002) Thymidylate synthase expression in colorectal cancer: a prognostic and predictive marker of benefit from adjuvant fluorouracil-based chemotherapy. J Clin Oncol 20: 1721-1728

Ermakova SP, Kang BS, Choi BY, Choi HS, Schuster TF, Ma W-Y, Bode AM, Dong Z (2006) (-)-Epigallocatechin gallate overcomes resistance to etoposide-induced cell death by targeting the molecular chaperone glucose-regulated protein 78. Cancer Res 66: 9260-9269

Gavioli M, Luppi G, Losi L, Bertolini F, Santantonio M, Falchi AM, D'Amico $\mathrm{R}$, Conte PF, Natalini G (2005) Incidence and clinical impact of sterilized disease and minimal residual disease after preoperative radiochemotherapy for rectal cancer. Dis Colon Rectum 48: $1851-1857$

Gosens MJ, Dresen RC, Rutten HJ, Nieuwenhuijzen GA, van der Laak JA, Martijn H, Tan-Go I, Nagtegaal ID, van den Brule AJ, van Krieken JH (2008) Preoperative radiochemotherapy is successful also in patients 
with locally advanced rectal cancer who have intrinsically high apoptotic tumours. Ann Oncol 19: 2026-2032

Guillem JG, Chessin DB, Cohen AM, Shia J, Mazumdar M, Enker W, Paty PB, Weiser MR, Klimstra D, Saltz L, Minsky BD, Wong WD (2005) Longterm oncologic outcome following preoperative combined modality therapy and total mesorectal excision of locally advanced rectal cancer. Ann Surg 241: 829-836; discussion 836-838

Guo B, Cao S, Tóth K, Azrak RG, Rustum YM (2000) Overexpression of Bax enhances antitumor activity of chemotherapeutic agents in human head and neck squamous cell carcinoma. Clin Cancer Res 6: $718-724$

Hamilton SR, Aaltonen LA (2000) Pathology and Genetics Tumours of the Digestive System. World Health Organization Classification of Tumours Lyon, France: IARC Press

Hertzberg RP, Caranfa MJ, Hecht SM (1989) On the mechanism of topoisomerase I inhibition by camptothecin: evidence for binding to an enzyme-DNA complex. Biochemistry 28: 4629-4638

Hsiang YH, Hertzberg R, Hecht S, Liu LF (1985) Camptothecin induces protein-linked DNA breaks via mammalian DNA topoisomerase I. J Biol Chem 260: $14873-14878$

Hsiang Y-H, Liu LF (1988) Identification of mammalian DNA topoisomerase I as an intracellular target of the anticancer drug camptothecin. Cancer Res 48: $1722-1726$

Jakob C, Liersch T, Meyer W, Baretton GB, Häusler P, Schwabe W, Becker $\mathrm{H}$, Aust DE (2005) Immunohistochemical analysis of thymidylate synthase, thymidine phosphorylase, and dihydropyrimidine dehydrogenase in rectal cancer (cUICC II/III): correlation with histopathologic tumor regression after 5-fluorouracil-based long-term neoadjuvant chemoradiotherapy. Am J Surg Pathol 29: 1304-1309

Johnston PG, Benson III AB, Catalano P, Rao MS, O'Dwyer PJ, Allegra CJ (2003) Thymidylate synthase protein expression in primary colorectal cancer: lack of correlation with outcome and response to fluorouracil in metastatic disease sites. J Clin Oncol 21: 815-819

Kim CS, Cho SH, Chun HS, Lee SY, Endou H, Kanai Y, Kim do K (2008) $\mathrm{BCH}$, an inhibitor of system $\mathrm{L}$ amino acid transporters, induces apoptosis in cancer cells. Biol Pharm Bull 31: 1096-1100

Kornmann M, Schwabe W, Sander S, Kron M, Strater J, Polat S, Kettner E, Weiser HF, Baumann W, Schramm H, Häusler P, Ott K, Behnke D, Staib L, Beger HG, Link KH (2003) Thymidylate synthase and dihydropyrimidine dehydrogenase mRNA expression levels: predictors for survival in colorectal cancer patients receiving adjuvant 5-fluorouracil. Clin Cancer Res 9: 4116-4124

Krajewski S, Blomqvist C, Franssila K, Krajewska M, Wasenius VM, Niskanen E, Nordling S, Reed JC (1995) Reduced expression of proapoptotic gene BAX is associated with poor response rates to combination chemotherapy and shorter survival in women with metastatic breast adenocarcinoma. Cancer Res 55: 4471-4478

Lee E, Nichols P, Spicer D, Groshen S, Yu MC, Lee AS (2006) GRP78 as a novel predictor of responsiveness to chemotherapy in breast cancer. Cancer Res 66: 7849-7853

Liersch T, Langer C, Ghadimi BM, Kulle B, Aust DE, Baretton GB, Schwabe W, Hausler P, Becker H, Jakob C (2006) Lymph node status and TS gene expression are prognostic markers in stage II/III rectal cancer after neoadjuvant fluorouracil-based chemoradiotherapy. J Clin Oncol 24: $4062-4068$

Misra UK, Deedwania R, Pizzo SV (2005) Binding of activated alpha2macroglobulin to its cell surface receptor GRP78 in 1-LN prostate cancer cells regulates PAK-2-dependent activation of LIMK. J Biol Chem 280: $26278-26286$

Nakano T, Oka K, Ishikawa A, Morita S (1997) Correlation of cervical carcinoma c-erb B-2 oncogene with cell proliferation parameters in patients treated with radiation therapy for cervical carcinoma. Cancer 79: $513-520$

Negri FV, Campanini N, Camisa R, Pucci F, Bui S, Ceccon G, Martinelli R, Fumagalli M, Losardo PL, Crafa P, Bordi C, Cascinu S, Ardizzoni A (2008) Biological predictive factors in rectal cancer treated with preoperative radiotherapy or radiochemotherapy. Br J Cancer 98: $143-147$

Oken MM, Creech RH, Tormey DC, Horton J, Davis TE, McFadden ET, Carbone PP (1982) Toxicity and response criteria of the Eastern Cooperative Oncology Group. Am J Clin Oncol 5: 649-655

Pinedo HM, Peters GF (1988) Fluorouracil: biochemistry and pharmacology. J Clin Oncol 6: 1653-1664
Ranganathan AC, Zhang L, Adam AP, Aguirre-Ghiso JA (2006) Functional coupling of p38-induced up-regulation of BiP and activation of RNAdependent protein kinase-like endoplasmic reticulum kinase to drug resistance of dormant carcinoma cells. Cancer Res 66: 1702-1711

Rau B, Sturm I, Lage H, Berger S, Schneider U, Hauptmann S, Wust P, Riess H, Schlag PM, Dörken B, Daniel PT (2003) Dynamic expression profile of p21WAF1/CIP1 and Ki-67 predicts survival in rectal carcinoma treated with preoperative radiochemotherapy. J Clin Oncol 21: 3391 - 3401

Raybaud-Diogene H, Fortin A, Morency R, Roy J, Monteil RA, Têtu B (1997) Markers of radioresistance in squamous cell carcinomas of the head and neck: a clinicopathologic and immunohistochemical study. J Clin Oncol 15: 1030 - 1038

Reddy RK, Mao C, Baumeister P, Austin RC, Kaufman RJ, Lee AS (2003) Endoplasmic reticulum chaperone protein GRP78 protects cells from apoptosis induced by topoisomerase inhibitors: role of ATP binding site in suppression of caspase-7 activation. J Biol Chem 278: 20915-20924

Rödel C, Grabenbauer GG, Papadopoulos T, Bigalke M, Günther K, Schick C, Peters A, Sauer R, Rödel F (2002) Apoptosis as a cellular predictor for histopathologic response to neoadjuvant radiochemotherapy in patients with rectal cancer. Int J Radiat Oncol Biol Phys 52: 294-303

Rödel C, Martus P, Papadoupolos T, Fuzesi L, Klimpfinger M, Fietkau R, Liersch T, Hohenberger W, Raab R, Sauer R, Wittekind C (2005) Prognostic significance of tumor regression after preoperative chemoradiotherapy for rectal cancer. J Clin Oncol 23: 8688-8696

Ruo L, Tickoo S, Klimstra DS, Minsky BD, Saltz L, Mazumdar M, Paty PB, Wong WD, Larson SM, Cohen AM, Guillem JG (2002) Long-term prognostic significance of extent of rectal cancer response to preoperative radiation and chemotherapy. Ann Surg 236: 75-81

Sakata T, Ferdous G, Tsuruta T, Satoh T, Baba S, Muto T, Ueno A, Kanai Y, Endou H, Okayasu I (2009) L-type amino-acid transporter 1 as a novel biomarker for high-grade malignancy in prostate cancer. Pathol Int 59: $7-18$

Saltz LB, Cox JV, Blanke C, Rosen LS, Fehrenbacher L, Moore MJ, Maroun JA, Ackland SP, Locker PK, Pirotta N, Elfring GL, Miller LL (2000) Irinotecan plus fluorouracil and leucovorin for metastatic colorectal cancer. Irinotecan Study Group. N Engl J Med 343: 905-914

Sato T, Kokuba Y, Koizumi W, Hayakawa K, Okayasu I, Watanabe M (2007) Phase I trial of neoadjuvant preoperative chemotherapy with S-1 and irinotecan plus radiation in patients with locally advanced rectal cancer. Int J Radiat Oncol Biol Phys 69: $1442-1447$

Sauer R, Becker H, Hohenberger W, Rödel C, Wittekind C, Fietkau R, Martus P, Tschmelitsch J, Hager E, Hess CF, Karstens JH, Liersch T, Schmidberger H, Raab R (2004) Preoperative versus postoperative chemoradiotherapy for rectal cancer. $N$ Engl J Med 351: $1731-1740$

Sinicrope FA, Ruan SB, Cleary KR, Stephens LC, Lee JJ, Levin B (1995) bcl-2 and p53 oncoprotein expression during colorectal tumorigenesis. Cancer Res 55: $237-241$

Sobin LH, Wittekind C (2002) UICC TNM Classification of Malignant Tumours, 6th edn : New York: Wiley-Liss

Stoeber K, Tlsty TD, Happerfield L, Thomas GA, Romanov S, Bobrow L, Williams ED, Williams GH (2001) DNA replication licensing and human cell proliferation. J Cell Sci 114: 2027-2041

Suzuki T, Sadahiro S, Fukasawa M, Ishikawa K, Kamijo A, Yasuda S, Makuuchi H, Ohizumi Y, Murayama C (2004) Predictive factors of tumor shrinkage and histological regression in patients who received preoperative radiotherapy for rectal cancer. Jpn J Clin Oncol 34: 740 - 746

Tanaka M, Riddell RH, Saito H, Soma Y, Hidaka H, Kudo H (1999) Morphologic criteria applicable to biopsy specimens for effective distinction of inflammatory bowel disease from other forms of colitis and of Crohn's disease from ulcerative colitis. Scand J Gastroenterol 34: $55-67$

Teranishi N, Naito Z, Ishiwata T, Tanaka N, Furukawa K, Seya T, Shinji S, Tajiri $\mathrm{T}$ (2007) Identification of neovasculature using nestin in colorectal cancer. Int J Oncol 30: 593-603

Wang JC, Dick JE (2005) Cancer stem cells: lessons from leukemia. Trends Cell Biol 15: 494-501

Willett CG, Warland G, Hagan MP, Daly WJ, Coen J, Shellito PC, Compton CC (1995) Tumor proliferation in rectal cancer following preoperative irradiation. J Clin Oncol 13: 1417 - 1424

Zlobec I, Vuong T, Compton CC, Lugli A, Michel RP, Hayashi S, Jass JR (2008) Combined analysis of VEGF and EGFR predicts complete tumour response in rectal cancer treated with preoperative radiotherapy. $\mathrm{Br} J$ Cancer 98: $450-456$ 